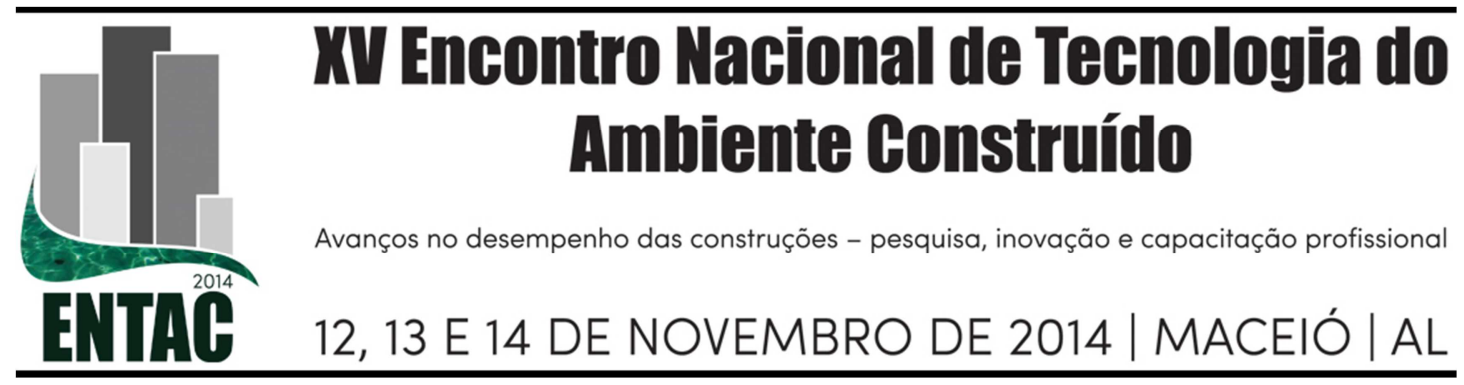

\title{
DIFICULDADES PARA A IMPLANTAÇÃO DE SOFTWARES INTEGRADORES DE PROJETO (BIM) POR ESCRITÓRIOS DE PROJETOS DE CIDADES DO NORDESTE DO BRASIL
}

\author{
MACIEL, Marcelo (1); OLIVEIRA, Fernando (2); SANTOS, Débora (3)
}

(1) Universidade Federal de Sergipe, (79)8105-5003, e-mail: mamaciel@ oi.com.br (2) Universidade Federal de Sergipe, e-mail: fernandomarcio@ hotmail.com, (3) Universidade Federal de Sergipe, e-mail: deboragois@yahoo.com.br

\begin{abstract}
RESUMO
A tecnologia BIM vem sendo implementada no desenvolvimento de projetos. O objetivo deste trabalho é analisar quais são as maiores dificuldades para se implantar a tecnologia BIM nos escritórios de arquitetura e urbanismo e nos escritórios que desenvolvem projetos complementares, em cidades do nordeste do Brasil. Este artigo é parte da pesquisa desenvolvida para uma dissertação de Mestrado e demonstra os resultados finais obtidos. Para isto, foi avaliada a atuação desses escritórios, por meio de entrevistas estruturadas realizadas através de questionários diferenciados para escritórios de projetos de arquitetura e urbanismo e escritórios que desenvolvem projetos complementares, ao adotar a estratégia de pesquisa estudo de caso. Foi feita uma caracterização dos escritórios pesquisados e buscou-se ainda a relação com os projetos complementares e as ações que contribuem para a redução de perdas. Verificouse que existe resistência na adoção de softwares BIM, pois quem o utiliza no desenvolvimento dos projetos, apresenta o produto aos clientes por meio do CAD. Observou-se ainda que os projetistas, apesar de identificarem algumas perdas no desenvolvimento de seus trabalhos, não têm conhecimento dos princípios enxutos. Como resultado, as empresas pesquisadas indicam interesse em utilizar a nova tecnologia.
\end{abstract}

Palavras-chave: BIM. Modelagem Integrada do Edifício. Perdas. Construção Enxuta. CAD.

\begin{abstract}
BIM technology has been implemented in the development of projects. The aim of this paper is to analyze what are the main difficulties to implement BIM in architecture offices and offices that develop complementary projects, in cities of northeastern Brazil. This article is part of research conducted for a Master thesis and demonstrates the final results. For this, it was evaluated the performance of these offices, through structured interviews using different questionnaires for project offices of architecture and urbanism and offices that develop complementary projects, by adopting the strategy of research case study. The offices were characterized and it was searched relationship with the complementary projects and actions that contribute to reducing wastes. It was found that there is resistance in the adoption of BIM software, because who uses it in the development of projects, presents product to customers through $C A D$. It was also observed that designers, despite identifying some wastes in the development of its work, have no knowledge of lean principles. As a result, the surveyed companies indicate interest in using the new technology.
\end{abstract}

Keywords: BIM. Building Integrated Modelling. Wastes. Lean Construction. CAD.

\section{INTRODUÇÃO}

Com a implantação de programas de Desenho Auxiliado por Computador (CAD), no início da década de 1980, houve um ganho em produtividade no desenvolvimento de 
projetos para a construção civil, mas, ainda assim, sua representação técnica continuou sendo pouco amigável para os que não são acostumados a trabalhar com esta técnica.

Recentemente, começou a ser utilizada a Modelagem da Informação da Construção, conhecida como tecnologia BIM, que agrega uma grande quantidade de informações ao modelo trabalhado, uma vez que várias disciplinas são integradas em um único modelo, que é compartilhado entre todos os profissionais envolvidos no projeto.

Segundo Goes e Santos (2011), os softwares BIM podem integrar um grande número de informações em um único banco de dados paramétrico, no qual vários profissionais trabalham simultaneamente em um mesmo arquivo, a partir do qual são geradas as diversas plantas e planilhas que compõem o empreendimento.

Entre as novas tecnologias e técnicas gerenciais, destaca-se a Engenharia Simultânea, que se refere a um processo de projeto caracterizado por uma análise prévia dos requisitos, a incorporação das restrições das fases subsequentes ainda na fase conceitual e ao controle de alterações até o fỉm do processo de projeto. Ciclos de interação são transferidos para as fases iniciais entre os membros da equipe. A compressão no tempo de projeto, o aumento do número de interações e a redução do número de alterações são os três maiores objetivos da engenharia simultânea (KOSKELA, 1992).

Assim, ao serem aplicadas novas tecnologias de informação para a elaboração e execução de projetos nos empreendimentos, conforme identificado em pesquisas bibliográficas, buscou-se com esta pesquisa analisar quais são as dificuldades para se implantar a tecnologia BIM nos escritórios de arquitetura e urbanismo e nos escritórios que desenvolvem projetos complementares, em cidades do nordeste do Brasil.

\section{REVISÃO BIBLIOGRÁFICA}

A construção enxuta refere-se à adaptação dos conceitos e princípios do Sistema Toyota de Produção (STP), com foco na redução das perdas, aumento de valor para o consumidor e aperfeiçoamento contínuo (SACKS et al., 2009).

Neste contexto, Ohno (1997) e Shingo (1996) propõem sete categorias de perdas para sustentar o processo sistemático de identificação e eliminação dessas. São perdas por superprodução, transporte, processamento em si, fabricação de produtos defeituosos, movimentação, espera e estoque. Seraphim et al. (2010) apresentam uma adaptação dos tipos de perdas para promover melhorias nos processos de projeto (Quadro 1). Na perda por transporte, pode ser levada em consideração a falta de interoperabilidade entre os diferentes sistemas computacionais.

Koskela (2004) cita a oitava categoria de perdas, making-do, que surge quando uma tarefa é iniciada, sem que todos os seus insumos estejam disponíveis, ou quando a execução de uma tarefa continua, mesmo quando um dos insumos necessários para sua realização acaba. Para Bahtla e Leite (2012), esforços de otimização são focados em fazer o fluxo de trabalho confiável, em oposição à melhoria da produtividade.

Segundo Fabricio (2002), o processo de Projeto envolve todas as decisões e formulações que visam subsidiar a criação e a produção de um empreendimento, indo da montagem da operação imobiliária, passando pela formulação do programa de necessidades e do projeto do produto até o desenvolvimento da produção, o projeto "as built" e a avaliação da satisfação dos usuários com o produto. 


\section{Quadro 1 - As sete perdas no Escritório de Projeto}

\begin{tabular}{cl}
\hline Tipo de perda & \multicolumn{1}{c}{ Escritório } \\
\hline Processamento sem valor & Uso incorreto de procedimentos ou sistemas inadequados. \\
Superprodução & $\begin{array}{l}\text { Geração de mais informação, em meio eletrônico ou papéis, além do que } \\
\text { se faz necessário, ou antes, do correto momento. }\end{array}$ \\
Inventário (estoque) & Alto volume de informação armazenado (buffer sobrecarregado). \\
$\begin{array}{c}\text { Defeito (fabricação de } \\
\text { produtos defeituosos) }\end{array}$ & $\begin{array}{l}\text { Erros frequentes de documentação, problemas na qualidade dos serviços } \\
\text { ou baixa performance de entrega. }\end{array}$ \\
Transporte & Utilização excessiva de sistemas computacionais nas comunicações. \\
Movimentação & Movimentação excessiva de pessoas e informações. \\
Espera & Períodos de inatividade das pessoas e informações (aprovação de \\
assinatura, aguardar fotocópias, esperar ao telefone).
\end{tabular}

Fonte: Adaptado de Seraphim et al. (2010).

Para Baccarini (1996) apud Tillmann (2012), os projetos de construção são caracterizados pelo envolvimento de organizações independentes e diversificadas, tais como consultores e prestadores de serviços, por um período de tempo finito.

Devido à grande influência do projeto sobre o produto final edificação, Barros (1999) apud Souza (2009) aponta o "projeto como elemento estratégico no processo de inovação tecnológica do setor de construção de edifícios, sendo o processo de projeto um elemento estratégico para se alcançar maior nível de competitividade". Isto acontece porque quando se pensa em executar um empreendimento, diversas fases devem ser cumpridas até a conclusão da obra. Em todas as etapas, existem custos associados e graus de interferência no andamento do serviço. Nas etapas iniciais, onde são definidos os parâmetros da edificação, o programa de necessidades e o projeto arquitetônico, a implicação das alterações no custo final do empreendimento é significativamente menor do que durante o andamento da construção ou até no uso do mesmo (FABRICIO, 2002).

Observa-se que a relação projeto e tecnologia da informação foi intensificada com a evolução da informática, ocorrida na segunda metade do século $\mathrm{XX}$, que levou ao desenvolvimento de equipamentos e softwares cada vez mais eficientes. O setor da construção civil se beneficiou com este avanço, com a adoção das planilhas eletrônicas, que auxiliam na fase de planejamento e gerenciamento dos empreendimentos, bem como dos programas gráficos, que deram velocidade ao desenvolvimento dos diferentes projetos associados aos empreendimentos imobiliários, tais como projetos arquitetônicos, estruturais, de instalações, dentre outros (AYRES FILHO, 2009; FABRICIO, 2002).

No contexto da construção civil, o aumento da complexidade dos processos acarretou na necessidade de inserção de uma mentalidade industrial, buscando a aplicação de soluções adotadas na indústria da manufatura. Neste sentido, a noção de modelagem de produto adotada por outras indústrias deu origem ao Building Information Modeling (BIM), como uma modelagem que busca integrar todos os processos relacionados à construção do produto edificação (SOUZA et al., 2009).

Os novos recursos, que estão associados à tecnologia BIM, podem trazer ganhos a todas as etapas de um projeto, pois os diferentes atores envolvidos trabalham em um mesmo modelo, diminuindo assim a ocorrência de conflitos entre as diversas disciplinas e trazendo um ganho de produtividade, com a redução do retrabalho e do tempo de ajustes nos diversos projetos que compõem o empreendimento (ANDRADE, 2012).

Além da importância do uso dos softwares paramétricos, em especial do modelo BIM, é importante destacar que diversos autores citam as dificuldades encontradas para a adoção destes softwares pelos escritórios de projeto do Brasil, tais como: a escassez de 
mão de obra especializada, a resistência à mudança, o alto investimento com máquinas e treinamento (SOUZA, 2009).

Vergara e Beiza (2012), em estudo realizado no Chile, afirmam que as dificuldades e os desafios observados em estudo dos escritórios de projeto relacionam-se com as barreiras econômicas, que existem para as empresas e os pequenos escritórios, a falta de apoio público à inovação nesta área de negócio e a falta de programas de treinamento adequados às reais necessidades da indústria. Já na Alemanha, uma grande barreira para os usuários que não trabalham com o BIM parece ser o capital necessário para investimento. Para os que já utilizam software BIM, o aspecto financeiro não é uma barreira ou problema (BOTH, 2012).

Segundo Checcucci, Pereira e Amorim (2013), a difusão do BIM no Brasil ainda é pequena, embora tenha crescido ao longo dos últimos anos. Utilizando classificação de Tobin (2008), o estágio predominante de adoção é o BIM 1.0.

\section{METODOLOGIA}

A estratégia de pesquisa adotada foi o estudo de caso, onde foi feita uma amostragem da quantidade de escritórios que atuam no mercado sergipano, para a seleção das empresas a serem entrevistadas. As empresas selecionadas foram escolhidas dentre as que têm maior número de registros de atividades em seus respectivos conselhos (Conselho de Arquitetura e Urbanismo - CAU e Conselho Regional de Engenharia e Agronomia CREA), nas cidades em que atuam.

Foram feitas visitas e entrevistas em escritórios que incorporaram ou não a tecnologia BIM no seu processo de projetação, a fim de que se possa entender os recursos disponíveis com o uso desses softwares e comparar o grau de utilização dos mesmos nos escritórios e empresas pesquisados em cidades do Nordeste do Brasil.

Para o levantamento de campo foram elaborados dois questionários estruturados, com grande parte das questões fechadas, a fim de sistematizar melhor o resultado da avaliação pela tabulação dos dados. Assim, foi elaborado então um questionário para os projetistas de arquitetura e urbanismo e outro para escritórios que trabalham com projetos complementares. Nestes documentos, os responsáveis pelos projetos caracterizavam suas empresas quanto ao tipo de projetos desenvolvidos, dimensionamento da mão de obra, tempo para desenvolvimento de projeto, adoção da tecnologia BIM e tipos de perdas no processo de projeto (Quadro 2), de acordo com as teorias estudadas.

Ao todo, foram feitas entrevistas, com os proprietários dos escritórios de: arquitetura e urbanismo (14), sendo oito que atuam no mercado sergipano (considerados os mais produtivos) e seis que estão sediados em outras capitais de estados do Nordeste - dois na Bahia e um em cada um dos estados de Alagoas, Pernambuco, Rio Grande do Norte e Maranhão, e projetos complementares (quatro empresas sergipanas). Em todos os casos, os respondentes foram os proprietários das respectivas empresas.

Esta pesquisa contém resultados parciais de uma dissertação de Mestrado, na qual, além dos agentes citados, foram entrevistadas as equipes responsáveis pelos projetos em empresas construtoras e incorporadoras. 


\section{Quadro 2 - Perguntas comuns aos dois questionários}

- Campo de atuação.

- Composição das equipes de trabalho.

- Questões referentes à adoção do BIM no processo de projeto.

- Quais são as dificuldades encontradas para a adoção da tecnologia e a previsão, quando existente, de sua implantação.

- Questões quanto à compatibilização de projetos e o emprego do BIM pelos outros projetistas.

- Quais são as perdas encontradas na empresa e as causas para suas ocorrências. Adoção dos conceitos da construção enxuta.

- Tempo médio empregado no desenvolvimento dos diferentes tipos de projeto.

- Ao final da aplicação do questionário, foi solicitado aos entrevistados que dessem uma nota de zero a dez em termos de sua percepção individual quanto às mesmas perguntas finais feitas no questionário dos projetistas: 1- Quantidade de vezes que o projeto retorna da obra; e 2- Quantidade de visitas à obra para resolver problemas.

Fonte: Elaborado pelos autores.

\section{RESULTADOS}

\subsection{Empresas de Arquitetura e Urbanismo}

$\mathrm{Na}$ pesquisa com os escritórios de arquitetura e urbanismo (AU), verificou-se que estas empresas, quando constituídas, têm um pequeno número de profissionais. Considerando todo o universo desta pesquisa, a quantidade média de arquitetos e urbanistas por escritório de projetos foi de 3,5 profissionais, o que demonstra que são empresas enxutas, com pequena quantidade de funcionários.

Dois terços dos entrevistados desenvolvem projetos AU, principalmente, acompanham obras e realizam projetos executivos. Apenas quatro dos respondentes informaram que também fazem os projetos complementares. Com relação à composição das equipes, na grande maioria dos escritórios pesquisados há a predominância de arquitetos e urbanistas. Foram registrados ainda os profissionais técnicos em edificações, engenheiros civis e engenheiros com outras formações, bem como estagiários de arquitetura e urbanismo e de engenharia civil (Figura 1).

Quanto aos tipos de projetos desenvolvidos, também foi levado em consideração o tempo despendido em cada escritório para a entrega final ao cliente. Neste caso, pode-se observar que há discrepância, quando se trata de um mesmo tipo de projeto (arquitetura de interiores). O tempo despendido para elaborar projetos variou de um a doze meses. Esta diferença pode significar o tamanho e a quantidade dos ambientes trabalhados, bem como a característica do tipo de projeto, uma vez que, nestes casos, há o comprometimento maior de tempo na escolha dos materiais e na sua finalização, pois exige uma maior interação com o cliente e maior disponibilidade de tempo para visitas a lojas e fornecedores (Figura 2).

Partindo para as questões que versavam sobre a tecnologia aplicada no desenvolvimento dos projetos, foi identificado que a maioria dos profissionais que participou desta pesquisa tem conhecimento do BIM (78,5\%), mas que apenas $21,4 \%$ deles utilizam a ferramenta com regularidade. Dentre as empresas consultadas, uma única empresa, neste caso, sediada em Sergipe, afirma que já utilizou softwares com esta tecnologia, mas que, no momento, não está utilizando por falta de demanda.

Dentre as empresas que informaram conhecer, aproximadamente metade delas demonstrou o interesse em trabalhar com BIM em um prazo de doze meses. Os que já utilizam (apenas três empresas pesquisadas) trabalham há, no máximo, vinte e quatro meses, excetuando-se uma das empresas sediadas na Bahia, que afirmou trabalhar com 
o BIM há treze anos. Em todos os casos, o software já adotado ou que virá a ser utilizado é o Autodesk ${ }^{\mathrm{TM}}$ RevitArchitecture TM.

Figura 1 - Profissionais na Equipe

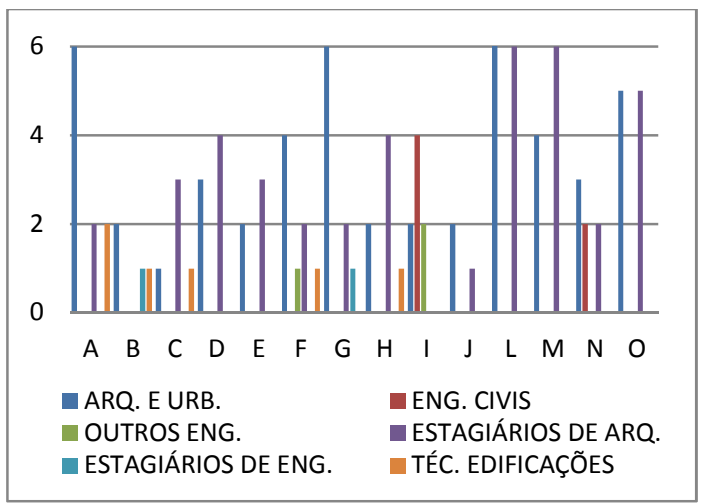

Figura 2 - Projetos Desenvolvidos (meses)

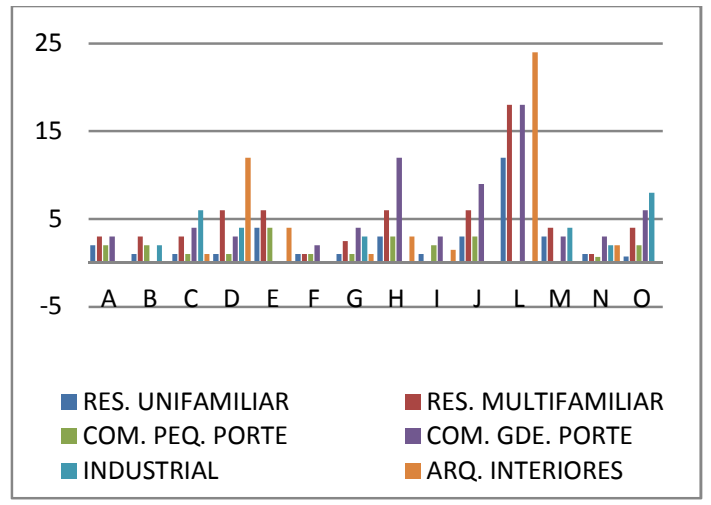

Fonte: Elaborado pelos autores.

Na pergunta sobre quais as dificuldades encontradas para a implantação do BIM nas empresas, as razões mais destacadas foram a falta de informação sobre os programas existentes; a falta de mão de obra já treinada; o alto custo para sua implantação, uma vez que os softwares exigem máquinas mais potentes e com grande capacidade de processamento; e a falta de exigência do mercado. Outros fatores também citados foram a alta rotatividade da mão de obra de estagiários e arquitetos nos escritórios, que desestimula o investimento em capacitação por parte das empresas; a falta de tempo para o aprendizado da nova tecnologia - esta foi uma das respostas mais recorrentes, assim como a dificuldade em convencer os profissionais a desenvolver uma nova maneira de projetar, o que faz com que continuem optando pelo CAD.

Na sequência, foi perguntado se é feita a compatibilização dos projetos de AU com os complementares. Neste caso, dez dos escritórios pesquisados informaram que fazem, dois disseram que fazem parcialmente e outros dois afirmaram que não fazem.

A terceira parte do questionário traz questões sobre a construção enxuta, onde se pretende entender se as empresas têm conhecimento ou se adotam os conceitos enxutos no seu dia a dia, cujos resultados consolidados podem ser encontrados no Quadro 3, ao final desta seção.

Quando perguntados sobre as causas para as perdas citadas por eles, os entrevistados deram mais ênfase à indecisão do cliente e à qualificação da mão de obra, mas também foram recorrentes as respostas relativas ao conflito entre os diversos projetos.

Quanto à percepção dos entrevistados sobre visitas e correções de projetos, observa-se que na pergunta de retorno do projeto da obra o resultado foi de 3,21 pontos em média. Com isto, percebe-se que eles não consideram muito recorrente o retorno dos projetos da obra para correções. Já em relação à segunda pergunta (visita à obra para solucionar problemas), a média foi de 4,21 pontos, superior à primeira, mas, ainda assim, não é considerado um valor significativo (Figura 3). Com isto, a integração dos projetos e o planejamento e a gestão das obras apresenta fragilidade.

Outra observação relevante é que, segundo as notas dadas, o retorno do projeto da obra é inversamente proporcional às visitas à obra para solucionar problemas, o que, de certa forma, demonstra uma lógica em relação às questões, ou seja, quanto mais visitas são feitas, menor a quantidade de vezes que o projeto retorna da obra para correções. Na 
segunda questão, a dispersão entre as notas dadas foi significativamente maior do que na primeira pergunta.

Figura 3 - Necessidade de ajustes nos projetos dos escritórios de projeto

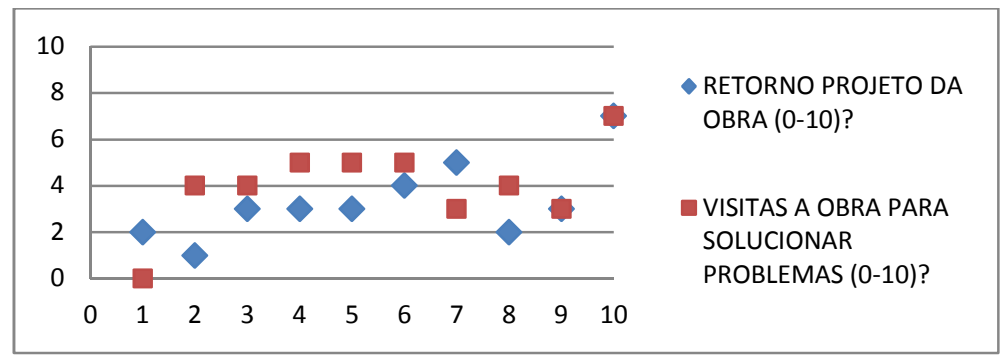

Fonte: Elaborado pelos autores.

Pode-se então aferir que, na percepção dos entrevistados, após a finalização dos projetos, não existe grande necessidade de mudanças durante a obra, pois as médias das notas foram baixas.

\subsection{Empresas de Engenharia que fazem projetos complementares}

$\mathrm{Na}$ pesquisa com escritórios de Engenharia, que fazem projetos complementares, sediadas na cidade de Aracaju, foram entrevistadas quatro empresas que se destacam no mercado local com esta atividade. Apesar de ser um número muito pequeno de empresas, elas são representativas pela quantidade e importância dos projetos que desenvolvem.

Observou-se que as empresas pesquisadas trabalham prioritariamente desenvolvendo projetos complementares (estrutural e de instalações) e executivos. Uma das empresas também trabalha com acompanhamento de obras e outra executa construção privada.

Com relação à composição das equipes, todas as empresas contam com Engenheiros Civis e, apenas uma das empresas pesquisadas não tem um arquiteto e urbanista no quadro de funcionários. Assim como a maior parte das outras empresas de projeto pesquisadas, os escritórios contam com poucos profissionais de nível superior - no máximo quatro, mas, têm uma maior variedade de técnicos envolvidos (Figura 4).

Quanto aos tipos de projetos desenvolvidos, também foi levado em consideração o tempo despendido em cada escritório para a entrega final ao cliente. Observou-se que há uma grande variação no tempo informado pelos respondentes sobre os projetos complementares e executivos. Enquanto a empresa A informa levar seis meses para prepará-los, a empresa B informa a metade deste tempo e a empresa $\mathrm{C}$ leva 15 dias para o primeiro caso e 40 dias para o segundo. Esta diferença pode ter alguma relação direta com a quantidade de engenheiros civis que trabalham em cada empresa, pois a relação de tempo é inversamente proporcional à quantidade desses profissionais, bem como associado ao tipo de projeto complementar desenvolvido (Figura 5).

Partindo para as questões que versavam sobre a tecnologia aplicada no desenvolvimento dos projetos, três dos entrevistados têm conhecimento do BIM, mas apenas um afirmou utilizar a ferramenta com regularidade, ou seja, há seis anos, utilizando o Eberick ${ }^{\mathrm{TM}}$ para projetos estruturais e de instalações. Este software foi citado por outros respondentes, como um interesse futuro, mas sem previsões de quando pretendem vir a adotar. 
Figura 4 - Profissionais na Equipe

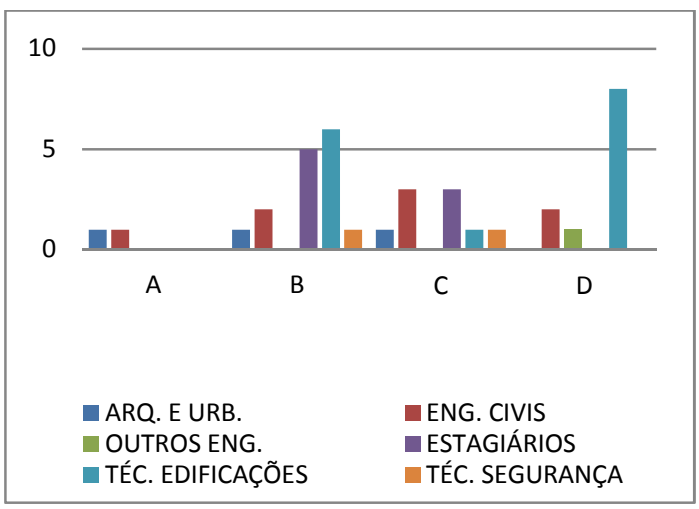

Figura 5 - Projetos Desenvolvidos (meses)

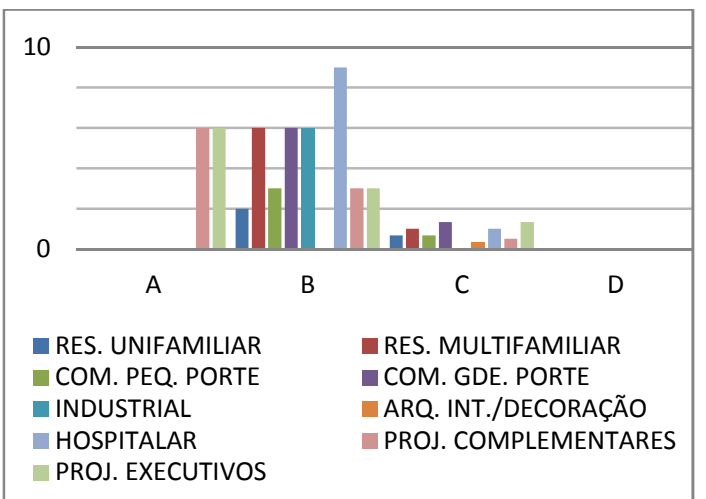

Fonte: Elaborado pelos autores.

Quando perguntados sobre as dificuldades encontradas em relação ao BIM, foi citado que o projeto arquitetônico já deveria vir modelado, a fim de que pudesse ter os projetos complementares trabalhados na mesma tecnologia. Outra opinião foi a falta de mão de obra especializada na área. Ao serem questionados se os fornecedores de projetos utilizam o BIM, metade dos entrevistados respondeu que não.

Na sequência, foi perguntado se é feita a compatibilização dos projetos de AU com os complementares. Neste caso, alguns entrevistados marcaram mais de uma resposta. Houve, porém, uma convergência das respostas, considerando como responsáveis pela compatibilização os autores dos projetos arquitetônicos e complementares, bem como uma empresa contratada para esta finalidade. Uma das empresas informou que toda a equipe envolvida no empreendimento fica responsável por esta atividade e marcou esta resposta em outros. Provavelmente o respondente teve a intenção de informar que cada projetista fica responsável pela compatibilização de seu projeto com os outros.

A terceira parte do questionário traz questões sobre a construção enxuta, onde se pretende entender se as empresas têm conhecimento ou se adotam os conceitos enxutos no seu dia a dia, como se pode verificar no Quadro 3.

Finalizando este questionário, foi solicitado aos entrevistados que dessem uma nota à percepção que eles têm sobre visitas e correções de projetos. Pode então ser observado que na pergunta de retorno do projeto da obra a média obtida foi de 1,5 pontos, enquanto que as visitas à obra para solucionar problemas tiveram uma média de 2,25 pontos (Figura 6). Em ambos os casos, as médias foram baixas, deixando claro que os entrevistados não consideram significativas estas atividades. A segunda pergunta teve uma dispersão maior, mas não foi significativa, principalmente porque uma das empresas consultadas não se manifestou nesta questão.

Figura 6 - Necessidade de ajustes nos projetos dos escritórios de projeto

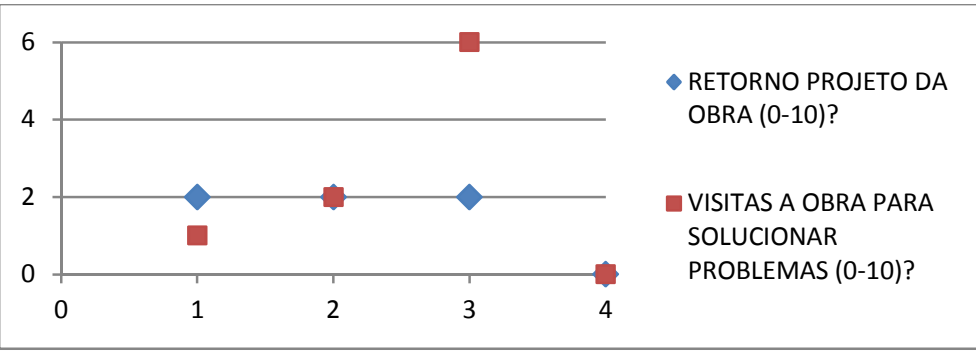

Fonte: Elaborado pelos autores. 
Pode-se então aferir que, na percepção destes entrevistados, após a finalização dos projetos, também não existe grande necessidade de mudanças durante a obra, ao menos no que diz respeito à presença do projetista no local da construção, corroborando com as respostas dos questionários respondidos pelos escritórios de arquitetura.

\section{Quadro 3 - Perdas identificadas nas empresas pesquisadas}

\begin{tabular}{|c|c|c|}
\hline Tipo de perda & Visão das empresas para perda & Perdas identificadas \\
\hline $\begin{array}{c}\text { Processamento sem } \\
\text { valor }\end{array}$ & $\begin{array}{l}\text { Perdas de material; } \\
\text { Perda de tempo dedicado a fazer } \\
\text { compatibilizações devido à mudança } \\
\text { de prioridade; } \\
\text { Mudanças nos órgãos reguladores; }\end{array}$ & $\begin{array}{l}\text { Retrabalho; } \\
\text { Mudanças legais, pois há perda de } \\
\text { tempo desenvolvendo o projeto com a } \\
\text { utilização de normas que não estão } \\
\text { mais em vigor; }\end{array}$ \\
\hline Superprodução & Mau uso dos materiais; & $\begin{array}{l}\text { Gastos com impressão e } \\
\text { detalhamento; }\end{array}$ \\
\hline Inventário (estoque) & Não identificado; & Estoque; \\
\hline $\begin{array}{l}\text { Defeito (fabricação } \\
\text { de produtos } \\
\text { defeituosos) }\end{array}$ & Falha nas especificações; & $\begin{array}{l}\text { Produtos defeituosos, decorrentes de } \\
\text { projetos arquitetônicos mal feitos; }\end{array}$ \\
\hline Transporte & Não identificado; & Não identificado; \\
\hline Movimentação & Má gestão de empreendimentos; & $\begin{array}{l}\text { Falta de domínio no uso de softwares; } \\
\text { Diferentes plataformas utilizadas, pois } \\
\text { é necessário fazer várias adequações } \\
\text { nos arquivos já prontos; }\end{array}$ \\
\hline Espera & $\begin{array}{l}\text { Falta de detalhamento; } \\
\text { Falta de compatibilização. }\end{array}$ & $\begin{array}{l}\text { Demora no licenciamento; } \\
\text { Velocidade do software; } \\
\text { Tempo de revisão e compatibilização } \\
\text { de projetos. }\end{array}$ \\
\hline
\end{tabular}

Fonte: Elaborado pelos autores.

\section{CONCLUSÃO}

Foi possível observar que, na região estudada, a adoção do BIM como ferramenta para projeto, planejamento e gerenciamento de empreendimentos ainda está ocorrendo de forma muito incipiente. Foi observado que vem sendo identificada por parte dos entrevistados, a necessidade de maior precisão nas informações trabalhadas em um empreendimento, como forma de redução de perdas e melhoria da qualidade.

As perdas listadas na literatura podem ser minimizadas ou até eliminadas a partir do uso do BIM, uma vez que o trabalho integrado entre os diferentes projetistas aumenta a qualidade do produto final. A partir do momento em que houver o interesse em se trabalhar simultaneamente, o BIM passará a ser utilizado de forma mais expressiva.

Enquanto os contratantes e usuários de projetos não decidirem investir na tecnologia BIM, o que será visto, serão experiências isoladas de alguns escritórios que têm maior interesse no uso destes recursos, sem uma maior interação com os outros projetos ou ganhos reais e significativos para a indústria como um todo.

É importante que se volte a este tema no futuro, a fim de se aferir se a adoção do BIM passará a ser uma realidade no setor de AEC como um todo e, não mais apenas, no desenvolvimento de grandes empreendimentos. 


\section{REFERÊNCIAS}

ANDRADE, L. S. A Contribuição dos sistemas BIM para o planejamento orçamentário das obras públicas: Estudo de caso do Auditório e da Biblioteca de Planaltina. 2012. 134 f. Dissertação (Mestrado em Arquitetura e Urbanismo). Programa de Pós-Graduação em Arquitetura e Urbanismo da Faculdade de Arquitetura e Urbanismo. Universidade de Brasíla, Brasília, 2012.

AYRES FILHO, C. Acesso ao modelo integrado do edifício. 2009. 254 f. Dissertação. Programa de PósGraduação em Construção Civil do Setor de Tecnologia. Universidade Federal do Paraná, Curitiba, 2009.

BHATLA, A.; LEITE, F. Integration Framework of BIM with the Last Planner System. In: ANNUAL CONFERENCE OF THE INTERNATIONAL GROUP FOR LEAN CONSTRUCTION, 20 ${ }^{\text {th }}, 2012$, San Diego, California. Proceedings... San Diego, 2012.

BOTH, P. V. Potentials and Barriers for Implementing BIM in the German AEC Market. In: EDUCATION AND RESEARCH IN COMPUTER AIDED ARCHITECTURAL DESIGN IN EUROPE CONFERENCE, 30, 2012, Praga, República Tcheca. Proceedings... Praga, 2012.

CHECCUCCI, E. S.; PEREIRA, A. P. C.; AMORIM, A. L. Uma visão da difusão e apropriação do paradigma BIM no BRASIL - TIC 2011. Gestão de Tecnologia de Projetos, São Paulo, v. 8, n. 1,p. 1939,jan./jun. 2013.

FABRICIO, M. M. Projeto Simultâneo na construção de edifícios. 2002. 350f. Tese (Doutorado em Engenharia de Construção Civil e Urbana). Escola Politécnica. Universidade de São Paulo, São Paulo, 2002.

GOES, R. H. D. T. E. B. D.; SANTOS, E. T. Compatibilização de Projetos: Comparação entre o BIM e CAD 2D. In: ENCONTRO DE TECNOLOGIA DE INFORMAÇÃO E COMUNICAÇÃO NA CONSTRUÇÃO, V, 2011, Salvador, Bahia. Anais...Salvador, 2011.

KOSKELA, L. Application of the new production philosophy to construction. Estados Unidos - Stanford, California. 1992. CIFE Tecnical Report, n. 72, 81p.

KOSKELA, L. 2004, Making do - the eighth category of waste, in: ANNUAL CONFERENCE OF THE INTERNATIONAL GROUP FOR LEAN CONSTRUCTION, 12, 2004, Helsingor, Denmark. Proceedings... Denmark. 2004.

OHNO, T, O Sistema Toyota de Produção: além da produção em larga escala. Porto Alegre: Bookman, 1997.

SACKS, R. et al. The Interaction of Lean and Building Information Modeling in Construction. Journal of Construction Engineering and Management, 2009.

SERAPHIM, E. C.; SILVA, I. B.; AGOSTINHO, O. L. Lean Office em organizações militares de saúde: estudo de caso do Posto Médico da Guarnição Militar de Campinas. Revista G\&P - Gestão \& Produção, São Carlos, v. 17, n. 2, p. 389-405, out. 2010.

SHINGO, S. O Sistema Toyota de Produção - do ponto de vista da engenharia de produção. Porto Alegre: Bookman, 1996.

SOUZA, L. L. A. Diagnóstico do uso do BIM em empresas de projeto de arquitetura. 2009. $108 \mathrm{f}$. Dissertação (Mestrado em Engenharia Civil). Programa de Pós-graduação em Engenharia Civil. Universidade Federal Fluminense, Niterói, 2009.

SOUZA, L; LYRIO, A.; AMORIM, S. Impactos do Uso do BIM em Escritórios de Arquitetura: Oportunidades no Mercado Imobiliário. Gestão \& Tecnologia de Projetos, vol. 4, nº 2, novembro 2009.

TILLMANN, P. A. A conceptual framework for improving value generation in complex construction projects. 2012. 227f. Tese (Doutorado em Engenharia). Programa de Pós-Graduação em Engenharia Civil da Universidade Federal do Rio Grande do Sul, Porto Alegre, 2012.

TOBIN, J. Proto-Building: To BIM is to Build. AECbytes "Building the Future", 28 maio 2008. Disponivel em: http://www.aecbytes.com/buildingthefuture/2008/ProtoBuilding_pr.html. Acessado em 11/01/2014.

VERGARA, M. L.; BEIZA, R. U. Desafíos y propuestas para la implementación de Building Information Modeling em Chile. In: CONGRESSO DA SOCIEDADE IBERO-AMERICANA DE GRÁFICA DIGITAL, 16, 2012, Fortaleza, Brasil. Proceedings... Fortaleza, 2012. 